\title{
EVOLUÇÃO DA LINHAGEM TRICHODERMA HARZIANUM P49P11 SELVAGEM QUANTO À PRODUÇÃO DE GLICOHIDROLÁSES POR TRATAMENTO MUTAGÊNICO PELO ETIL METANO SULFONATO (EMS) SEGUIDA DE SELEÇÃO POR VELOCIDADE DE FORMAÇÃO DE HALO EM AGAR-CELULOSE
}

\author{
P. S. $\operatorname{costA}^{1,4}$, I. C. $\operatorname{COSTA}^{2}$, A. C. $\operatorname{COSTA}^{1,4}$, P. S. DELABONA ${ }^{4}$, J. G. C. \\ PRADELLA ${ }^{4}$
}

\begin{abstract}
${ }^{1}$ Universidade Estadual de Campinas, Departamento de Engenharia Química ${ }^{2}$ Universidade Federal de Goias

${ }^{3}$ Centro de Pesquisa em Energia e Materiais/ Laboratório Nacional de Ciência e Tecnologia do Bioetanol

CTBE

${ }^{4}$ Centro de Pesquisa em Energia e Materiais, Laboratório Nacional de Ciência e Tecnologia do Bioetanol - CTBE
\end{abstract}

E-mail para contato: patríciacosta.ufv@gmail.com

RESUMO - As utilizações de técnicas de mutagênese clássica para fungos filamentosos, desde muitos anos, vêm sendo uma estratégia bastante atrativa para incrementar a produção de glicohidrolases. Esse trabalho teve como objetivo a realização da evolução de linhagens T. harzianum P49P11 selvagem quanto a produção de glicohidroláses por tratamento mutagênico pelo agente químico EMS seguida de seleção por velocidade de formação de halo em Agar-celulose. Com base nisso, dentre as trinta concentrações diferentes de EMS testadas foi possível acessar a concentração onde se obtêm 95\% de mortalidade, concentração essa onde se acessa cepas com altas frequências de mutações. Foi possível relacionar os resultados obtidos pela velocidade de formação de diâmetro de halo de celulose com a atividade de Fpase ao longo do tempo de uma fermentação padrão submersa. Obtiveramse possíveis mutantes promissores com relação á velocidade de formação de diâmetro de halo de hidrólise de celulolse pré-tratada. Os mutantes selecionados pela velocidade de formação do halo de hidrólise que foram fermentados de modo padrão mostraram uma elevação considerável da atividade das glicohidroláses comparada com a cepa selvagem. Este trabalho pode contribuir para posteriores estudos de melhoramento genético em fungos $T$. harzianum e para outros fungos filamentosos.

\section{INTRODUÇÃO}

Com o intuito de incrementar os níveis de produção de enzimas, linhagens fúngicas têm sido geneticamente modificadas para tentar obter organismos capazes de produzir elevados níveis de celulases (Chand et al., 2005). O material genético de um microrganismo pode ser modificado 


\section{9 a 22 de outubro de 2014 \\ Florianópolis/SC}

e essa modificação é capaz de ser transmitida aos descendentes. O resultado é o aparecimento de um indivíduo mutante distinguível do tipo original em uma ou mais características genéticas.

Atualmente diversas técnicas são empregadas para a obtenção de fungos mutantes hipercelulolíticos, como fusão de protoplastos (Cheng et al., 2009), irradiação por luz UV (Cheng et al., 2009), emprego de agentes químicos como o etil metil sulfonado (EMS) (Cheng et al., 2009), Brometo de etídio (EtBr), 1-metil-3-nitroguanidina (MNNG) (P.Chand et al., 2004), dentre outros.

Como base no texto acima, esse trabalho teve como objetivo a realização da evolução de linhagens T. harzianum P49P11 selvagem quanto a produção de glicohidroláses por tratamento mutagênico pelo agente químico EMS e a introdução da técnica "velocidade de crescimento do diâmetro do halo de hidrólise de celulose e observação da diferença entre as transparências de tais halos" para a literatura de melhoramento e seleção de fungos filamentosos hipercelulolíticos.

\section{Materiais e Métodos}

\subsection{Engenharia evolutiva clássica com o agente mutagênico EMS, aplicada ao fungo} filamentoso $T$. harzianum com o intuito de incrementar a produção de celulases para a hidrólise de biomassa lignocelulósica

\subsection{Confecção da curva de mortalidade por EMS para T. harzianum}

A linhagem parental T. harzianum foi cultivada em placas de PDA por 7 dias a $29^{\circ} \mathrm{C}$ para o desenvolvimento de esporos. Os esporos foram então suspendidos em solução salina ( $\mathrm{NaCl} ; 0,085 \%)$ e contados em câmara de Neubauer sob microscópio óptico. A concentração da suspensão de esporos foi ajustada para 1000 esporos/mL

Para que um processo de mutagênese seja eficiente, o tratamento com uma dose adequada de mutagênico é crucial. Em análise literária percebe-se a utilização de uma ampla faixa de concentração de EMS necessária para atingir os $95 \%$ de mortalidade para diferentes gêneros de fungos filamentosos. Com base nisso, foram realizadas duas curvas de mortalidade. A primeira foi realizada com o intuito de acessar o limite de concentração de EMS requerido para matar o fungo em estudo, onde foi testada uma ampla faixa de concentrações de EMS. Já a segunda curva tornou-se necessária para se atingir os $95 \%$ de mortalidade dentro de uma faixa mais restrita de concentrações, com base na primeira curva.

Para a confecção da primeira curva de mortalidade, $0,5 \mathrm{~mL}$ da suspensão de 1000 esporos/mL foram tratados com $0,5 \mathrm{~mL}$ do agente mutagênico EMS (Sigma-Aldrich) sob concentrações de 50,100, 150, 200, 250, 300, 350, 400, 450 e $500 \mu \mathrm{g} / \mathrm{mL}$, e 1, 2, 4, 6, 8, 10, 20, 40, 50, 80 e $100 \mathrm{mg} / \mathrm{mL}$ por 60 minutos a temperatura ambiente. Posteriormente, adicionou-se, 1 $\mathrm{mL}$ da solução de neutralização $\mathrm{Na}_{2} \mathrm{~S}_{2} \mathrm{O}_{3} \cdot 5 \mathrm{H}_{2} \mathrm{O} 5 \%(\mathrm{p} / \mathrm{v})$. Em seguida, $100 \mu \mathrm{L}$ das amostras foram plaqueadas em meio sólido de seleção, agar-celulose, decrito no item 2.3.1dsse trabalho, embrulhadas em papel alumínio e incubadas a $29{ }^{\circ} \mathrm{C}$ por 6 dias, ou até aparecerem as colônias. $\mathrm{O}$ número de colônias formadas foi contado para se obter a curva de mortalidade em relação à concentração limite de EMS que o fungo suporta. 


\section{9 a 22 de outubro de 2014 \\ Florianópolis/SC}

Percebeu-se, neste caso, que em 50mg/mL de EMS o fungo em estudo apresentava-se ainda com $100 \%$ de sobrevivência, porém em $80 \mathrm{mg} / \mathrm{mL}$ o mesmo já se apresentava com $100 \%$ de mortalidade. Com base nestes dados foi possível direcionar melhor as concentrações a serem testadas para a segunda curva de sobrevivência. Para a segunda curva de mortalidade foram testadas as concentrações de $0,55,60,63,66,69,72,75,78$ e $81 \mathrm{mg} / \mathrm{mL}$ de EMS. A curva foi confeccionada de modo idêntico à primeira, porém avaliando uma faixa mais estreita de concentração de EMS, como já mostrado. Dessa forma, foi selecionada a concentração onde se obteve $95 \%$ de mortalidade para ser utilizadas nas etapas de mutações posteriores. As colônias que foram obtidas nessa concentração e que apresentaram halos de hidrólise na placa de agarcelulose seguiram para a etapa de fermentação padrão submersa.

\subsection{Velocidade de formação de halos de hidrólise de celulose como método de seleção de mutantes hipercelulolíticos}

\subsubsection{Preparo meio sólido de seleção}

A celulose utilizada no meio agar-celulose é a swollen celufloc que é uma celulose que possui uma homogeneização mais eficiente em solução comparada com a celufloc comum. $\mathrm{O}$ preparo da swollen foi realizado da seguinte maneira: $5 \mathrm{~g}$ de Swollen celulose Celufloc 200 (Celuflok Industrial e Comercial de Celulose Ltda., Brasil) foram solubilizadas em $200 \mathrm{~mL}$ de água destilada, juntamente com $20 \mathrm{~g}$ de bolinhas de vidro e mantidas em shaker a $29{ }^{\circ} \mathrm{C}$ e 200 rpm por 7 dias (Camassola e Dillon, 2010).

O meio aga-celulose foi formulado com $1 \%$ (p/v) Swollen celulose Celufloc 200 (Celuflok Industrial e Comercial de Celulose Ltda., Brasil), 0,1\% (p/v) extrato de levedura (Sigma-Aldrich), 0,1\% (p/v) sacarose (Alamar Tecno Científica Ltda., Brasil), $10 \%$ (v/v) solução de sais minerais 20x concentrada, 0,1\% (v/v) Triton X-100, $2 \%$ (p/v) Agar e 1\% de deoxiglicose acrescida ao meio depois de autoclavado. Depois de autoclavado acrescentado ao meio $1 \%$ e posteriormente, $40 \mathrm{~mL}$ deste meio foi vertido em placas de petri de tamanho maior que a padrão.

\subsubsection{Aplicação do método da medida da velocidade de formação do diâmetro de halos de hidrólise em placas Agar-celulose}

Em uma placa de petri grande, contendo o meio sólido de seleção já especificado no item 2.3.1 foram inoculados pontos de inserção de esporos para cada possível mutante obtido, juntamente com a cepa selvagem (Figura 1 abaixo). A cepa selvagem foi colocada em todas as placas para comparar com os possíveis mutantes na mesma condição. As placas foram mantidas em estufa a $29^{\circ} \mathrm{C}$ por oito dias. O experimento foi feito em duplicata e as posições de cada cepa na placa foram colocadas aleatoriamente (Figura 1).

O diâmetro de formação do halo de degradação de celulose foi medido a cada 24 horas durante oito dias. Através das medidas dos diâmetros do halos de hidrólise ao longo dos dias foram geradas curvas de crescimento de diâmetro do halo, sendo essas utilizadas para o calculo da regressão ( $a$ exemplo $\mathrm{y}=\mathrm{ax}+\mathrm{b}$ ) onde se obtém o valor de " $a$ ", sendo este um dos parâmetros de medida pra esse experimento (Figura 1). 
À medida que a celulose vai sendo degradada no meio sólido de seleção percebe-se que ocorre um aumento na transparência da zona de degradação; o aumento da transparência da placa foi comparado também entre as cepas. Para essa avaliação foi intitulado, de forma visual, um sinal positivo (+) à medida que fosse aumentando a transparência da área de degradação.

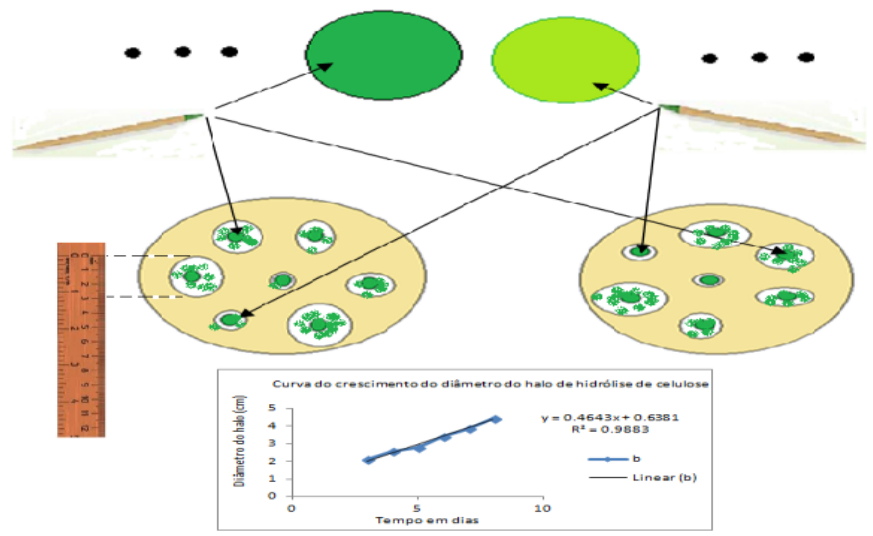

Figura 1: Ilustração do experimento da medida da velocidade de formação do halo de degradação da celulose e ilustração das zonas de degradação de celulose seguido da medição do halo, confecção da curva e calculo do "a".

\subsubsection{Fermentação padrão submersa como método de validação dos resultados obtidos pela velocidade de formação e transparência do diâmetro do halo de hidrólise em agar-celulose.}

Nesta etapa foram escolhidos alguns possíveis mutantes que se destacaram em pelo menos um dos aspectos testados pelo primeiro experimento, velocidade de crescimento do diâmetro do halo de hidrólise e os que apresentaram mais transparência no halo em geral, comparado sempre com a cepa selvagem. Se tratando que a técnica de velocidade de formação do diâmetro de halo de hidrólise é realizada ao longo de 8 dias pode-se comparar com a fermentação padrão submersa ao longo de 8 dias também, sendo essa uma boa estratégia de validação de tal método.

Os possíveis mutantes escolhidos nessa etapa foram submetidos a fermentações padrão em shaker por 168 horas a $29{ }^{\circ} \mathrm{C}$ em $200 \mathrm{~mL}$ de meio nas condições otimizadas por Delabona (2012b). Amostras foram retiradas nos tempos de 72, 96, 120, 144 e 168 horas de fermentação. As amostras foram centrifugadas e o sobrenadante foi reservado para a avaliação das atividades enzimáticas contra o substrato papel de filtro.

\section{RESULTADOS E DISCULSSÃO}

\subsection{Curva de mortalidade por EMS para T. harzianum linhagem P49P11}

Ao analisar a Figura 2 percebe-se que a concentração letal de EMS para o fungo em estudo está 
compreendida entre 50000 e $80000 \mu \mathrm{g} / \mathrm{mL}$ de EMS.

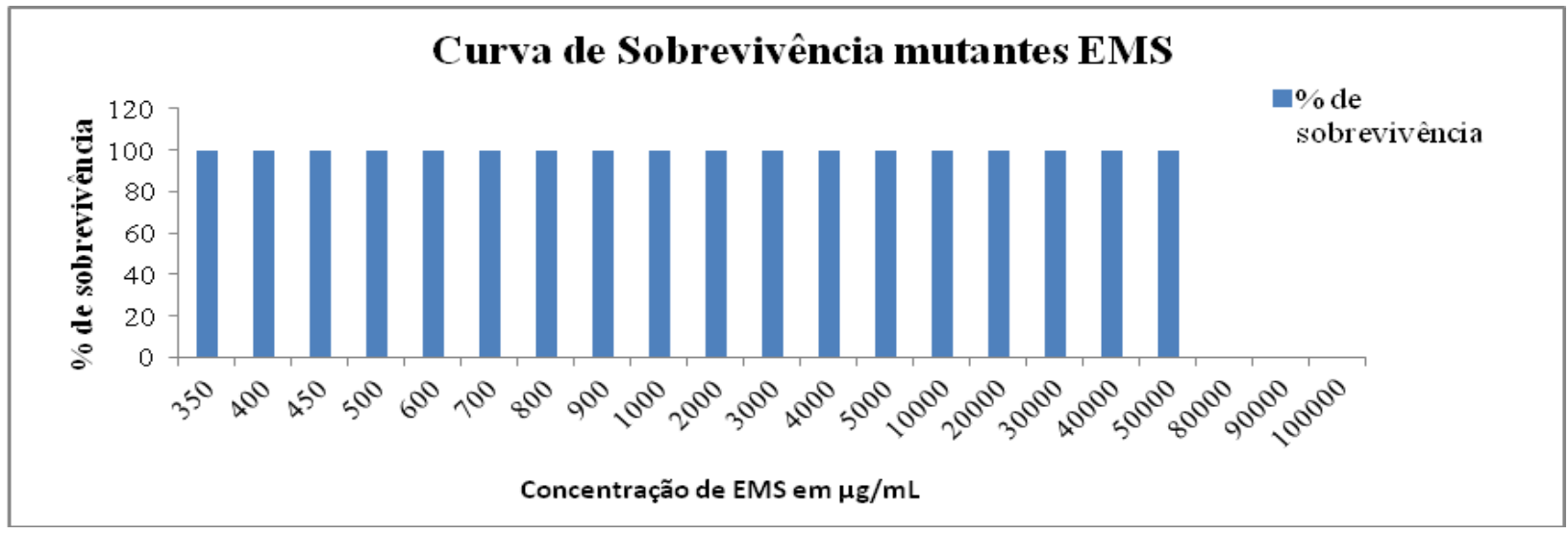

Figura 2: Primeira curva de sobrevivência de mutantes EMS para cepa selvagem do filamentoso Trichoderma harzianum linhagem P49P11

Através do resultado apresentado pela Figura 2 foi possível diminuir o intervalo de concentrações e acessar com maior facilidade a concentração em que se atinge $95 \%$ de mortalidade, resultado apresentado pela Figura 3.

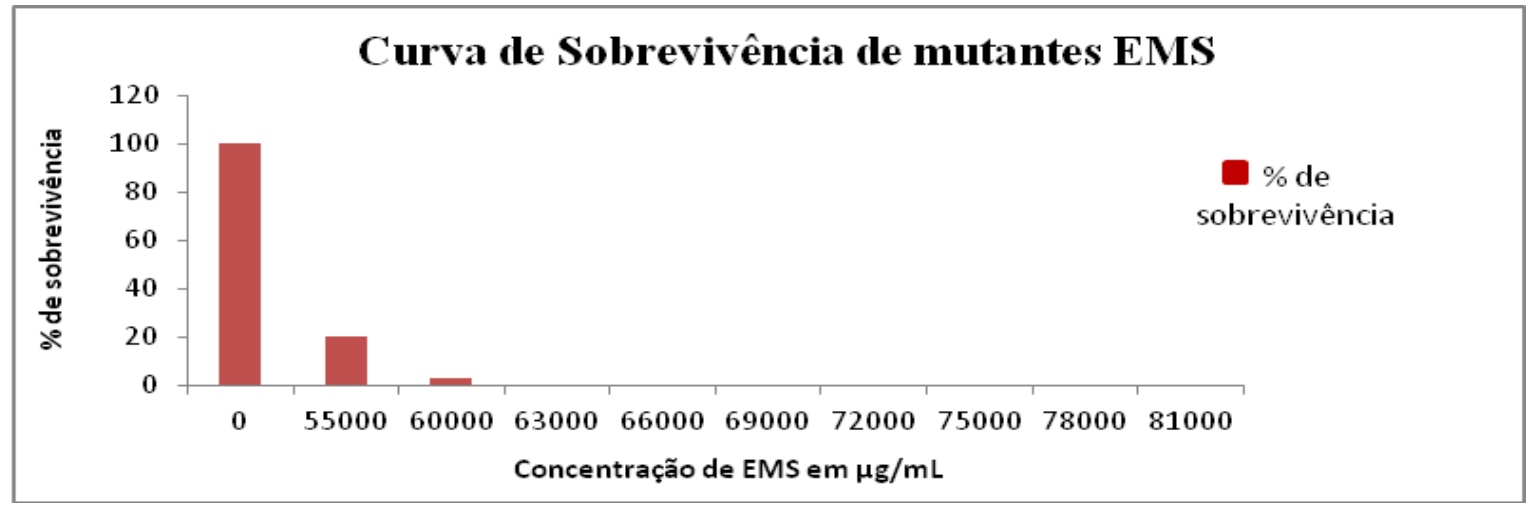

Figura 3: Curva de sobrevivência de mutantes EMS.

Percebe-se que essa concentração, onde se têm $95 \%$ de mortalidade esta compreendida entre $55 \mathrm{mg} / \mathrm{mL}$ (80\% de mortalidade) e $60 \mathrm{mg} / \mathrm{mL}$ (96\% de mortalidade). Através do calculo da concentração de EMS necessária para se acessar os $95 \%$ de mortalidade para as concentrações de 55 e $60 \mathrm{mg} / \mathrm{mL}$ obtidas, pode-se fazer a média estimativa da concentração, onde se tem um valor de $62,3437 \mathrm{mg} / \mathrm{mL}$ de EMS para se acessar a faixa de $95 \%$ de mortalidade. Os mutantes obtidos que apresentaram a presença de halo na placa agar-celulose foram para as etapas de seleção já mencionadas. 


\subsection{Seleção dos possíveis mutantes promissores}

\subsubsection{Velocidade de formação de halos de hidrólise de celulose como método preliminar de seleção de mutantes HMS hipercelulolíticos}

As Tabelas 1 e 2 abaixo mostram o resultado da seleção por velocidade de crescimento de halo de hidrólise e transparência do halo de degradação da celulose ao longo de 8 dias. O valor de "a" foi obtido pela equação da reta obtida pela curva de crescimento do diâmetro do halo ao longo de 8 dias de incubação a $29^{\circ} \mathrm{C}$.

Para a observação do perfil de resposta de seleção para essa técnica comparada com a fermentação submersa foram escolhidas, as cepas sombreadas em verde nas Tabelas 1 e 2, H44 (destacou-se com relação a transparência do halo ao longo do tempo para as duas duplicatas), H22 (destacou-se com relação a velocidade de crescimento do diâmetro do halo e pela transparência do halo para as duas duplicatas), H5 (destacou-se com relação a velocidade de crescimento do diâmetro do halo e pela transparência do halo para apenas uma das duplicatas).

Como sombreados nas tabelas abaixo, os possíveis mutantes produzidos a partir do agente químico EMS que se destacaram com relação ao selvagem $(\mathrm{H})$ foram os que apresentam-se em sombreados (verde e cinza) sendo as cepas H44 (Tabela 1), com relação á velocidade de formação da transparência do halo de hidrólise em celulose, e todos o possíveis mutantes da Tabela 2 menos as cepas H52 e H50. A fermentação das cepas sombreadas em cinza será realizadas em futuros experimentos que darão continuidade a esse trabalho.

Tabela 1: Resultado da seleção por velocidade de crescimento de halo de hidrólise e transparência do halo de degradação de celulose ao longo de 8 dias pelas duplicatas dos possíveis mutantes EMS. O "a" é descrito por uma curva de crescimento do diâmetro do halo ao longo de 8 dias de incubação a $29^{\circ} \mathrm{C}$.

\begin{tabular}{|c|c|c|c|c|}
\hline Colônia & a & $\mathbf{R}^{\mathbf{2}}$ & $\begin{array}{c}\text { Soma da transparência do halo ao } \\
\text { longo de } \\
\text { 8 dias }\end{array}$ \\
\hline H18 & 0.5286 & 0.9931 & & \\
\hline H26 & 0.5164 & 0.995 & 2 & \\
\hline H12 & 0.5 & 0.9843 & & \\
\hline H & 0.53 & 0.9977 & 5 & \\
\hline H44 & 0.5014 & 0.9992 & 6 & 6 \\
\hline H7 & 0.5057 & 0.984 & 2 & \\
\hline H27 & 0.4729 & 0.9934 & & \\
\hline H84 & 0.4943 & 0.9978 & 3 & \\
\hline & 0.5214 & 0.996 & 5 & \\
\hline & & & & \\
\hline
\end{tabular}

Tabela 2: Resultado da seleção por velocidade de crescimento de halo de hidrólise e transparência do halo de degradação de celulose ao longo de 8 dias pelas duplicatas dos possíveis mutantes EMS. O "a" é descrito por uma curva de crescimento do diâmetro do halo ao longo de 8 dias de incubação a $29^{\circ} \mathrm{C}$. 


\begin{tabular}{|c|c|c|c|c|}
\hline Colônia & $\mathbf{a}$ & $\mathbf{R}^{\mathbf{2}}$ & \multicolumn{2}{|c|}{$\begin{array}{c}\text { Soma da transparência do halo ao longo } \\
\text { de 8 dias }\end{array}$} \\
\hline H2 & 0.55 & 0.9919 & 3 & \\
\hline H4 & 0.5057 & 0.9894 & 4 & \\
\hline H11 & 0.5343 & 0.9814 & 3 & 5 \\
\hline H25 & 0.5164 & 0.984 & 6 & 4 \\
\hline H1 & 0.5086 & 0.985 & 5 & \\
\hline H5 & 0.5057 & 0.9847 & & \\
\hline H & 0.5114 & 0.9933 & 5 & \\
\hline H52 & 0.4971 & 0.9834 & & \\
\hline H50 & 0.4486 & 0.9496 & 1 & \\
\hline
\end{tabular}

3.2.2 Fermentação padrão submersa para validação da técnica de seleção por velocidade de formação do diâmetro do halo de hidrólise de celulose e como ultimo método de seleção dos possíveis mutantes EMS obtidos

O resultado de fermentação submersa apresentado pela Tabela 3 indica um forte tendência ao acerto com relação a técnica de velocidade de crescimento do diâmetro do halo de hidrólise da celulose como um método eficiente para seleção de mutantes hipercelulolíticos.

O possível mutante $\mathrm{H} 22$ apresentou dois picos de Fpase em 72 e em 144 horas de cultivo ( 0,92 e $0,94 \mathrm{FPU} / \mathrm{mL}$ respectivamente) (Tabela 3 ) o que pode ser relacionada com o maior "a" (Tabela 2), comparado ao selvagem e a maior transparência do halo com relação as cepas H5 e H (Tabela 2).

O possível mutante $\mathrm{H} 5$ apresentou um maior pico de atividade em 72 horas de cultivo (Tabela 3), sendo a sua atividade maior que todos as outras cepas testas no tempos de 72 horas, o que pode estar relacionada com a maior velocidade específica de crescimento do diâmetro do halo de hidrólise de celulose com relação as cepas H22 e H (Tabelas 1 e 2).

O possível mutante $\mathrm{H} 44$ apresentou uma atividade menor comparada com o selvagem no tempo de 72 horas, porém nos outros tempos apresentou atividade melhor em relação a cepa selvagem apresentando o seu pico de atividade em 120 horas $(0,916 \mathrm{FPU} / \mathrm{mL})$. Isso se equivale com o resultado de velocidade do diâmetro de hidrólise de celulose que apresentou menor "a" em relação ao selvagem porém, maior transparência do halo com relação ao selvagem (Tabela 1).

Tabela 3: Resultado da validação do método de seleção por velocidade de crescimento de halo de hidrólise e transparência do halo de degradação de celulose ao longo de 8 dias pelas duplicatas dos possíveis mutantes EMS. Fermentação submersa padrão dos possíveis mutantes escolhidos a partir do tópico 3.2.1.

\begin{tabular}{|c|c|c|c|c|}
\hline \multirow{2}{*}{ Tempo de cultivo } & \multicolumn{4}{|c|}{ Atividade de Fpase em FPU/mL dos possíveis mutantes } \\
\cline { 2 - 4 } & $\mathbf{H}$ & $\mathbf{H 2 2}$ & $\mathbf{H 5}$ & $\mathbf{H 4 4}$ \\
\hline 72 & 0,8832 & 0,9298 & 0,9785 & 0,8624 \\
\hline 96 & 0,7834 & 0,6469 & 0,8572 & 0,8974 \\
\hline 120 & 0,8342 & 0,8724 & 0,8131 & 0,916 \\
\hline 144 & 0,7191 & 0,9414 & 0,7804 & 0,7804 \\
\hline
\end{tabular}




\section{CONCLUSÃO}

O presente estudo nos permite concluir as seguintes questões:

- Foi possível acessar a concentração de EMS adequada para acessar a taxa de 95\% de mortalidade para o fungo em estudo.

- Foi possível relacionar os resultados obtidos pela velocidade de formação de diâmetro de halo de celulose com a fermentação padrão submersa.

- Foi possível obter cepas que podem ser possíveis mutantes promissores com relação as atividade das glicohidrolases, sendo esses estudados mais a fundo em próximos trabalhos em continuação deste.

- O restante dos mutantes obtidos serão todos submetidos a fermentação submersa em experimentos futuros para assim selecionar um mutante promissor e validar de forma mais concreta a aplicação da técnica apresentada por esse trabalho.

\section{REFERÊNCIAS}

CAMASSOLA, M; DILlON, A. J. P. Cellulases and Xylanases production by Penicillium echinulatum grown on sugar cane bagasse in solid-state fermentation. Applied Biochemistry Biotechnology. 162, 1889-1900, 2010.

CHAND, P., ARUNA, A., MAQSOOD, A. M., \& RAO, L. V.. Novel mutation method for increased cellulase production. Journal of Applied Microbiology,98(2), 318-323. 2005.

DELABONA. P. S, FARINAS CS, SILVA MR, AZZONI SF, PRADELLA, JGC. Use of a new Trichoderma harzianum strain isolated from the Amazon rainforest with pretreated sugar cane bagasse for on-site cellulase production. Bioresour Technol 107: 517-521, 2012a.

MANDELS, M.; REESE, E. T. Induction of cellulase in Trichoderma viride as influenced by carbon sources and metals. The Journal of Bacteriology, v. 73(2), p. 269-278, 1957.

P. CHAND, ARUNA, A., MAQSOOD, A. M., \& RAO, L. V. Novel mutation method for increased cellulase production. Journal of Applied Microbiology,98(2), 318-323, 2005. 